\title{
Towards the application of interaction design to digital TV content development
}

\author{
Francisco A. P. Fialho ${ }^{\mathrm{a},}{ }^{,}$, Paloma Maria Santos ${ }^{\mathrm{a}}$, Marcus de Melo Braga ${ }^{\mathrm{a}}$ and Anelise Thaler ${ }^{\mathrm{a}}$ \\ ${ }^{a}$ Post-Graduate Program in Engineering and Knowledge Management, Federal University of Santa Catarina, Campus \\ Universitário, Florianópolis, Santa Catarina, Brazil
}

\begin{abstract}
Television can be considered one of the main means of mass entertainment. It occupies an important place in people's lives, influencing behavior and creating and/or enforcing consumer's habits and needs. With the advent of Digital Television, a series of new features tend to further impact upon society in many different ways. The main agent of this change is interactivity, which is the leverage that will transform the traditional viewer's role. Interactivity turns the viewer into a user, a partner who receives the content, but also produces, participates and collaborates during the viewing process. This paper aims to discuss the importance of applying interaction design in the development of projects related to digital television. The main factors that may contribute to improve the interaction design in applications for digital TV were identified drawing on a descriptive and qualitative method of investigation. The results showed that the interface design for this new media should not only be aesthetically appealing, but should also focus on usability (i.e. user's wishes and needs). Additionally, the creation of these interfaces requires the investigation of some characteristics and limitations of device interaction, considering the choice of colors, saturation levels and brightness, avoiding graphic symbols and prioritizing the navigation through the numerical buttons of the remote control.
\end{abstract}

Keywords: interaction design, digital television, interactivity, usability, ergonomics

\section{Introduction}

A design is an idea, a project or a plan for solving a particular problem. It consists of the embodiment of an idea in order to enable its transmission with the aid of corresponding means to other means. As human language is not sufficient for such transmission, preparation of sketches, designs, models and samples constitutes the means to make an idea visually perceptible [11].

Design is also fundamental to the field of Digital TV (DTV), since it can enhance the experience of interaction in that it considers important aspects relating to the development of user interface.

Almeida and Garcia [1] highlight that the DTV interface has, as a differential in relation to the interface of a traditional computer program, the fact that communication and, consequently, interaction ${ }^{*}$ occur in real time. This feature increases the complexity of the environment.

According to Becker [4], however, IHC studies are still very recent, even in the computing field. Nevertheless, they have borne important contributions so as to set requirements for usability, ergonomics, and the behavior of users in relation to the system. In the case of traditional TV systems, such definitions are essential as until now the viewer has been receiving information only by means of audio and video.

This viewpoint is particularly admirable in relation to the nature of DTV, as this model of communication involves interaction between different people around a common goal. This puts new perspective on the challenges of DTV design, as in these situations of

*Corresponding author. fialho@deps.ufsc.br 
mediated interaction, certain factors must be carefully designed to ensure that people, who are participating in the process, can perceive what is the state of the interaction, who has the word, among other aspects [1].

The use of this technology will result in a social and cultural diversity that needs to be prepared to understand its advantages and benefits. This way the applications must be determined by socio-cultural characteristics of the target audience, causing the user to be stimulated by the attractiveness of interfaces, simplified and user-friendly tools for digital TV.

This study consists of a composite theoretical framework in the areas of interaction design, technology, cognitive science and usability for digital TV.

\section{Graphical user interfaces (GUIs) for digital TV}

Unlike other media that were born interactive (e.g. computers), television becomes interactive after a long time of existence and coexistence with the public. By connecting interactivity to television, the development of design must always observe the viewer's baggage and customs based on the simplicity of approaching information by means of this mass communication vehicle.

Gomes [8] emphasizes that the environment in which television is watched is one of the factors that influence design solutions for an interactive interface. It is also necessary to assess how viewers are accustomed to using the remote control and their behavior that often varies with the social context in which they are inserted, their age and even the time of day that the interactive program is running.

Junot [9] stresses that the inclusion of interactive resources in television is a major challenge for specialists in TV production and this challenge requires the participation of different segments of society. Regardless of the technology adopted and the outcome of discussions, research and testing, the current language of television can be considered a point of departure for interactive programming.

From the perspective of the viewer, Junot [9] suggests that "the interaction with the television content can be performed by graphical interfaces overlapping video, whose functions can be activated by buttons on the remote control."

According to Oliveira, Queiroz-Neto and Maeta [14], the remote control is the means by which the user interacts with the GUI, and should get to know their characteristics and limitations to apply maximum usability in its possible use.

This means that the relationship of these interfaces can be of at least three types: (i) overlay (in which the interface covers part of the video); (ii) resizing (in which the video is resized to a smaller size and becomes an element within the GUI); or (iii) total coverage (in which the GUI entirely covers the video, making it invisible). The options of overlay and resizing can interfere with language and audiovisual narrative.

With overlay the aesthetic problems with the video can be evidenced. If the images are captured with more closed framing planes, the chances of an actor or presenter to have part of their faces covered by the GUI will be larger. In certain situations, apart from creating a visual noise, this will also cause the loss of relevant information from video content, making it difficult to understand the narrative.

Junot [9] adds that in this context, the television production must adopt a video language that considers the interactions of the viewer the instant interactivity is available, avoiding more closed framing planes and using a composition of scene that leaves room for the display of interfaces.

Whether for technical reasons or willingly, many people will be able to watch TV only as passive viewers, where the space left for displaying graphical user interfaces in the video, may be filled with scenarios and background elements that provide balance to the image by complying with the so-called "rule of thirds" and avoiding any visual pollution. This way the content will be absorbed by all the people involved (i.e. televiewers or teleusers) in the most natural way as possible.

With regard to aspects of graphical user interface, Oliveira Queiroz-Neto and Maeta [14] highlight the following aspects: Layout information - it organizes various types of information (text, images, icons, tables, etc.) that will be presented to the user; Color Scheme - it improves readability and highlights the information regarding the background screen and the perception of selected elements; Fonts - type and font 
size improve readability; Consistency - it standardizes presentation format so that users realize the cohesion between the different interfaces to access information; Cognitive Load - it shows that too much information on the screen may lead the user to confusion.

Gomes [8] argues that the great design challenge for interactive television is to make viewers notice artifacts in an interface that will encourage them to respond and take action against a background that previously did not demand much from their participation.

If an application prompts the curiosity of a user and this user proposes to interact, s/he must go through two other phases, a learning phase and another phase in which s/he will continue interacting with something that has proven to be easy to use and rewarding in respect of the content presented.

\section{Interaction design}

The term interaction design was created by designer Bill Moggidge, creator of the first portable computer (the GRiD Compass, 1981) in the late '90s, when microcomputers began to be disseminated. His fascination with the project and what people want from everyday things gave him a broad view of the information revolution.

Verplank [19] defines interaction design as design for people. For him, interaction design needs to answer three general questions: (i) How people act? Through affordances, real and perceived properties of an object, especially those that provide operational instructions, the way people act, manipulate or handle just by gazing; (ii) How do they feel? The effect of an action and its feedback; many of the emotions come from the sensory quality of the communication means with a machine or system, and (iii) how do these people understand? What is involved in the mental model of how to know what to do by presenting an overview of how objects or systems operate.

As Arnold [2] explains, this means the act of planning or making designs and in order to develop them it is necessary to know about their use and target audience as well as understand the restrictions related to material cost and feasibility.

The primary concern of interaction design is the creation of interactive projects, with products that are easy to learn, effective in its use and capable of providing a rewarding experience to those who use them.

For Fileno [5] interaction design is "the field of knowledge that studies how to create meaningful experiences for users through interactive products and services. The focus of Interaction Design is on human relations established by means of artifacts and interactive services".

Fileno [5] adds that the new term "interaction design" is not something ephemeral within design. The subject is still little widespread in Brazil, but in leading technology markets it has acquired significant status in professional and academic circles, with an international professional association (IxDA Interaction Design Association) and several Master's and Doctoral programs, such as the ones offered by The Ivrea, Royal College, Carnegie Mellon University and Umea.

Preece, Rogers and Sharp [17] argue that designing is a practical and creative activity whose final aim is develop products that help users achieve their goals. For this reason, when a new product is designed, it is necessary to have some understanding of what is expected of it.

Preece, Rogers and Sharp [17] argue that design has also to do with compensation, with the balance of competing needs. So much so that the right balance denotes experience, likewise, it requires the development and evaluation of alternative solutions.

When there is the involvement of users, it is important to capture and express a design in a suitable format, since users may not understand experts' annotations. One of the most effective solutions is the use of prototypes.

The main design purpose is the suggestion of ideas that meet these requirements. This alternative can be divided into two sub-activities: conceptual design and physical design. The first alternative involves the production of the conceptual model for a product, this model shows what the product should do, how it should behave and look like. The second takes into account details such as colors, sounds and images, design of menus and icons.

Developing a conceptual model involves displaying the product proposed, based on the users' needs and other identified requirements. To make sure that this model will be understood as intended, it is necessary 
to carry out iterative tests with the product while it is still being developed. A central point in this design process is to decide from the beginning what users will do in order to accomplish their tasks.

For Norman [13], a good design is also an act of communication between the designer and the user, except that all communication must be effected through the device interface itself, which should be self-explanatory. When designers fail to provide a conceptual model, one is forced to create his/her own model, and this model will be probably mistaken. The conceptual models are of critical importance to design.

Preece, Rogers and Sharp [17] add that when a set of possible ways of interaction in an interactive system is identified, the design of the conceptual model needs to be thought of in terms of concrete solutions. This involves thinking about the interface behavior, the particular styles of interaction that will be used and how this interface will look and feel.

The physical design in turn involves considering more concrete and detailed issues with respect to the design of an interface. There are many aspects relevant to the physical design of interactive products.

There is no rigid border between conceptual design and physical design. Interaction design is specifically interactive, so some questions may arise during the conceptual design, similarly, during the physical design it will be necessary to revisit decisions made during the conceptual design phase.

\section{The EGC Web 2.0 system}

A Virtual Learning Environment (VLE) can be defined as a medium that makes use of cyberspace to serve content, enabling the interaction between the actors and the mediation of the distance teachinglearning process [15].

According to Pereira, Schmitt and Dias [15], the main resources of a VLE can be grouped into four categories: (i) information and documentation, (ii) communication, (iii) administrative and pedagogical management and (iv) production. The information and documentation category presents the course institutional information, discloses its contents and didactic materials and enables the exchange of files with users. The category of communication enables synchronous and asynchronous communication among its users through forums, chats or e-mail lists. The category of administrative and pedagogical management deals with the evaluation of student performance and its relationship with the administrative sectors of the institution. Finally, the category of production is responsible for all the development process of the content production activities (Figure 1).

Virtual Learning Environments bring together in a single site, several tools that can be used to encourage interaction among all their users. Uzunboylu, Bicen and Cavus [18] present the creation of a VLE that integrates several Web 2.0 tools, such as photos, videos, networks, blogs, profiles, guestbooks and others, thus presenting satisfactory results from students.

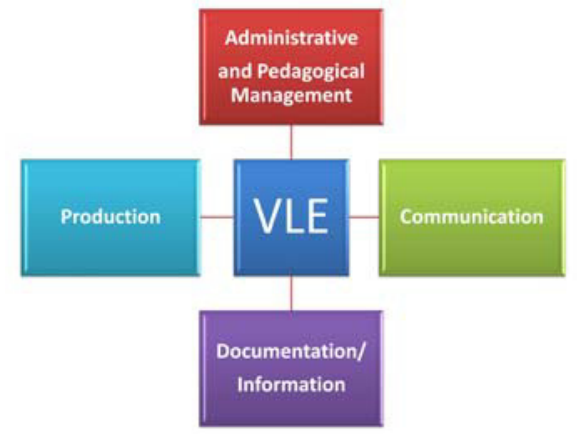

Figure 1. The four categories of a VLE (Source: [15])

The EGC Web 2.0 system, presented in this study, is a Virtual Learning Environment (VLE) developed as a support platform for the Postgraduate Program in Engineering and Knowledge Management at Federal University of Santa Catarina.

The system platform was developed with Drupal and has been in operation since 2009. It integrates features of user profiles, documents, contacts, notes, calendar, virtual communities and blogs. A team of systems engineers and design professionals participated in its design and construction.

The purpose of the EGC Web 2.0 Platform was integrate into an application, various features offered by Web 2.0 to create a single virtual learning environment, simplifying their use by postgraduate students.

The VLE design was defined considering the following actions: (i) meet the principles of usability 
and design, (ii) maintain the visual identity of the institution, (iii) be easy to use and maintain, (iv) support face-to-face and distance education (v) have nice visual user interface, (vi) provide a graphic language and structure that meets the needs of the target audience.

The initial design included the following functions: (i) $\log$ entry, (ii) my space, (iii) communities (iv) contact list (v) profile of users, (vi) document repository, (vii) calendar (viii) blogs. Apart from these features, the Web 2.0 EGC Platform also presents window messages and an event monitor.

In the following subsections, the techniques adopted for each component of this VLE graphic design project are presented.

\section{Method}

The purpose of the field research carried out in this study was to identify key factors that must be considered when implementing the processes of interaction design used in the development of the EGC Web 2.0 Platform for the Brazilian Digital TV model.

With this purpose in mind, a literature review was conducted to identify the key constructs that would inform the questionnaire used during the field research.

The first group of constructs was obtained from the studies by Kotler [10], which define the five main components of the design proposed here. According to [10], a design can also be conceptualized as an attempt to satisfy customers and organization's results by means of five basic components: (i) performance, (ii) quality, (iii) durability, (iv) appearance and (v) costs.

The five components suggested by Kotler [10] were used as constructs in the design of the first set of questions for the research instrument. In our particular case, the durability and costs components were replaced by security and benefits, respectively, because they are more suitable to the system being studied, once durability would not be applicable to software and cost would not make sense as access to the platform is free of charge.

In addition to these five constructs, the five basic elements of design were considered for evaluation in the research questionnaire: (i) Navigation Structure; (ii) Layout; (iii) Use of Color; (iv) Typography; and (v) Use of icons.

Finally, in order to complete the questionnaire, the ten heuristics put forward by Molich and Nielsen [12] - which are used to assess the usability of a system, especially in relation to interaction design - were adopted. These ten usability heuristics are listed as follows.

1. Visibility of system status (i.e. provide feedback to the user);

2. Match between system and the real world (i.e. speak the user's language);

3. User control and freedom (i.e. provide system outputs that are easily identifiable);

4. Consistency and standards (i.e. be consistent or coherent);

5. Help users recognize, diagnose, and recover from errors (i.e. provide good error messages);

6. Error prevention (i.e. help the user to prevent errors);

7. Recognize (identify goals and actions) without the need to memorize (i.e. minimize user memory load);

8. Flexibility and efficiency of use (i.e. provide shortcuts);

9. Aesthetic and minimalist design (i.e. provide simple and natural dialogues);

10. Help and documentation (i.e. provide usage information).

These heuristics were useful to design the research instrument administered to the users of the platform with the aim of assessing this platform usability.

\section{Results and discussion}

Table 1 shows the results of the evaluation of questions related to the EGC Web 2.0 graphic design project obtained in field research. 
Table 1

Evaluation of the graphic design project

\begin{tabular}{|l|c|}
\hline Question / Acronym & (1-5) \\
\hline 01. Project in General (GER) & 4 \\
\hline 02. Use of Colors (COR) & 4 \\
\hline 03. Typography (TYP) & 4 \\
\hline 08. Performance (PER) & 4 \\
\hline 09. Quality (QUA) & 4 \\
\hline 11. Appearance (APA) & 4. \\
\hline 12. Benefits (BEN) & 4 \\
\hline 13. VLE (General) (VLE) & 4 \\
\hline 04. Use of Icons (ICO) & 3 \\
\hline 05. Layout (LAY) & 3 \\
\hline 06. Navigation (NAV) & 3 \\
\hline 07. Usability (USA) & 3 \\
\hline 10. Security (SEC) & 3 \\
\hline
\end{tabular}

Table 1 shows that all questions received a score greater than or equal to 3 ("Normal" or "Neutral") which can be considered an acceptable value, especially considering that eight out of thirteen questions received an average evaluation score of 4 ("Good" or "Agree").

Table 2 presents the results from the evaluation of questions related to Jakob and Nielsen's 10 heuristics, taken as the basis for the questionnaire, in order to assess the interaction design questions.

Table 2

Evaluation of the 10 heuristics

\begin{tabular}{|l|c|}
\hline Heuristic / Acronym & (1-5) \\
\hline 02. Language (LAN) & 4 \\
\hline 01. Visibility (VIS) & 3 \\
\hline 03. Control (CON) & 3 \\
\hline 04. Patterns (PAT) & 3 \\
\hline 05. Treatment (TRE) & 3 \\
\hline 06. Errors (ERR) & 3 \\
\hline 07. Objectives (OBJ) & 3 \\
\hline 08. Shortcuts (SHO) & 3 \\
\hline 09. Unnecessary (UNN) & 3 \\
\hline 10. Help (HEL) & 3 \\
\hline
\end{tabular}

Figure 2 attempts at representing the results of the platform evaluation.

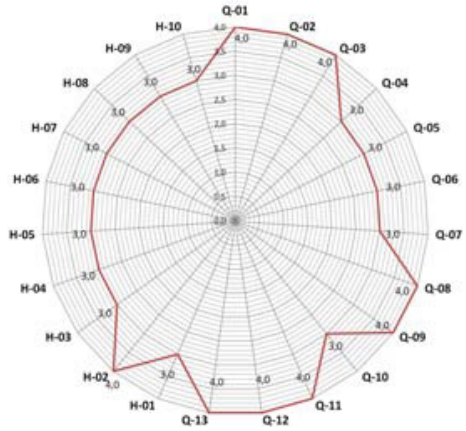

Figure 2. Median score of the answers

The radar plot shows clearly the proximity of all the items evaluated in field research to the maximum score (5).

As to the evaluation of interaction design, it can be observed that all usability heuristics had a median score greater than or equal to 3 , that is, they had a normal or "neutral" (3) evaluation. The second heuristic evaluation had a median score of 4 ("Agree").

Some aspects of design for interactive digital TV, which address factors necessary to design interfaces for this new media should not only be aesthetically pleasing to the eyes but also easy to use and compliant with the user's needs and desires.

The creation of user interfaces for interactive TV demands a study of their specificities and limitations regarding presentation and interaction devices, since the interface planning supports designers to create style and appearances. Interactive TV - apart from being a hub of communication - is the central source of information in a house [16].

Issues relating to mental models of users and designers need to be understood and addressed appropriately so that an acceptance level is achieved with users [7].

Interaction Design for Digital TV consists of four basic activities: identification of user needs; development of design alternatives; construction of iterative versions and design evaluation. It is important to highlight that these activities are interrelated and provide information to each other and they can also be repeated.

Interaction Design considers three aspects: focus on the user; definition of usability goals; and iteration. Focus on the user is central in the design process in 
that the process encourages and provides opportunities for user participation within the process. The usability criteria should be identified, agreed and documented early in the project and they are important when choosing design alternatives. Finally, iteration must be present, as it is through iteration that the refinement based on results from the evaluation of intermediate versions is allowed.

It is worth emphasizing the importance of making the interfaces of interactive television simple and quick to understand and use [3]. To achieve that, it is essential that the process of navigating between different screens is performed efficiently and with a low error rate. Freitas [6] lists some actions that might be helpful for easy navigation: guide the viewer, encourage interaction, leave clear instructions; decrease the number of clicks, always leave a visible way out, keep the viewer informed; relate content to metaphors and mental models widely disseminated; keep an eye out for consistency.

Piccolo [16] adds that the interaction between user and application occurs, for example, by selecting a menu option, filling out a form, navigating between pages, and making the remote control the main input device.

An important factor for the successful design of digital TV is related to the use of colors. According to [6], the process of color formation on television involves the following nomenclature: hue is the color itself, expressed as proportions of red, blue and green; saturation is the intensity of a color. The more it approaches its shade of gray, the color is less saturated; luminance is the brightness of the image, represented by gray scale values; and chrominance is a combination of hue and saturation values.

When defining saturation values for television, some care must be taken. Highly saturated colors, placed side by side, tend to conflate with each other, making it difficult to visualize the image. Tiresias (2009 cited in Freitas [6]) recommends the use of colors with up to $85 \%$ saturation.

Another recurring problem is the brightness value, as bright colors, especially white, are not well displayed on the TV screen. In order to display pure white, the TV device must adjust red, green and blue rays to maximum power. This intensity is so strong that the electricity on the screen becomes unbalanced, causing the so-called bloom effect, which consists of light curves around very clear areas of the screen [6].

Some of the specificities of an interaction with a TV set are mapped into guidelines, which aim to assist the developer of an application to use the devices best suited for this medium. Some of these guidelines are offered by broadcasters and content producers who suggest the correct TV use of colors, fonts, spacing on the screen, navigation mechanisms and other interactive devices.

Other guidelines to be observed are: use detached selectors, short texts on the screen to explain the steps that must be followed by the user (it is not recommended to use "help" for that purpose); avoid the use of graphic symbols; and prioritize the navigation by means of the numerical buttons of a remote control [ 16].

Another characteristic of the image formation on television screen that should be noted has do to with typography. Freitas [6] highlights the difficulty of using text on television screens. The predominant factors for this are classified as follows: lowresolution of an image; more often than not viewers are not accustomed to reading blocks of text on the screen; some set-top boxes do not have enough processing to apply anti-alias to the fonts; legibility problems when texts generated for $4: 3$ screens are stretched and displayed in 16:9 or when images generated for 16:9 screen are compressed for display on 4:3 screens, problems with color and with interlaced scanning, as previously mentioned, the text can be cut out if placed outside the safety margins.

In order to create effective text interfaces, some of the following guidelines should be considered: use size 24 for body fonts and under no circumstances less than 18, light colors on dark backgrounds are generally easier to read, they require larger spaces between the lines than printed texts, and whenever possible, spaces between words should be increased by $30 \%$, maximum of words displayed on the screen should be no more than 90 words, they should be broken into smaller blocks so that they can be read quickly.

Piccolo [16] suggests the use of the Tiresias font in applications for digital TV because of its greater legibility. This font was developed based on studies with users who suffer from some sort of visual 
impairment and it has presented good results in the digital TV environment.

\section{Final comments}

Interaction design is the area of design that deals with the promotion and avoidance of obstacles in interactions or communications between human beings and certain products or services. Design professionals in this area seek for knowledge about what design objects and how they behave and function. To achieve this, it is necessary to invest time in research, report analyses, and especially interaction, as interaction design is not only about computers and other equipment, but especially humans who are users of the systems analyzed, and must be included during the creation and corrective processes of a product.

The attitude of people in relation to television should be seen as an active rather than a passive, as interaction - even in conventional TV systems - does not occur with the device directly, it can give rise actions and discussions. Taking these actions and discussions as input to the design of interaction and interfaces within the paradigm of digital television, it is important to highlight the responsibility of designers for the appropriation of all the innovative potential of new technology in order to facilitate the communication of the intended information, anchored in social principles without compromising success factors of traditional television.

By and large, this study sought to understand how the transposition of the relevant interaction design principles occurs in the Brazilian digital TV context. It is hoped that this will contribute to the implementation of interaction design in the development of consistent graphical interfaces presenting interactive content. This in turn lists the most relevant interaction design processes that allow for the viability of the Brazilian digital TV system.

Efforts to improve the usability of a design should always be oriented to the final product, associated with ergonomic features, memory load, attitude and type of user interaction. These considerations are essential nowadays, as users are increasingly in search of easy-to-navigate, pleasant and attractive GUIs.

By achieving the aim of this research in identifying the processes that may be considered relevant for the implementation of the interaction design principles in the Brazilian digital TV context, we expect to contribute to the implementation of consistent graphical user interfaces in the presentation of interactive content so that interaction design may also contribute to the viability of Brazilian Digital TV.

Interaction design is much more than just an optimization of devices and other equipment that are used to facilitate human life. It is far beyond humancomputer interaction, making objects pleasing to all senses and feelings. Prior to focusing on aspects related to functioning, profitability and market success, interaction design is concerned with making the use of this product exciting and able to influence, directly and positively, the lives of its users.

\section{References}

[1] Almeida, Leonelo Dell Anhol; Garcia, Laura Sánchez. Aspectos comunicativos, sociais e psicológicos da televisão tradicional e implicações no design de aplicações para o Sistema Brasileiro de Televisão Digital. In: Workshop: Usabilidade de Aplicações e Tecnologias Emergentes: a Necessidade de uma Nova Usabilidade?, 2006, Natal, 2006.

[2] Arnaldo, Tatiane Cristine. Além da interação homemcomputador: O Design de Interação, seus processos e metas, em busca da satisfação do usuário final. Available at $<$ http://www.designemartigos.com.br/wpcontent/uploads/2010/07/design_de_interacao.pdf $>$. Accessed on January 20, 2011.

[3] Barros, Gil Garcia. A consistência da interface com o usuário para a TV interativa. 2006. Dissertação (Mestrado em Engenharia). Escola Politécnica da Universidade de São Paulo, Universidade de São Paulo (USP), São Paulo.

[4] Becker, Valdecir. Concepção e desenvolvimento de aplicações interativas para televisão digital. Florianópolis, 2006. $100 \mathrm{f}$. Dissertação (Mestrado) - Universidade Federal de Santa Catarina, Centro Tecnológico. Programa de Pós-Graduação em Engenharia e Gestão do Conhecimento.

[5] Fileno, Érico. Design de interação. Available at $<$ http://ericofileno.wordpress.com/tag/interacao/>. Accessed on January 20, 2011.

[6] Freitas, Paulo Vinícius. Design de Interação e Televisão Digital: a construção do Aplicativo Interativo Beach Soccer. 2010. Monografia (Graduação em Desenho Industrial). Universidade Federal do Espírito Santos. Available at $<$ http://www.tvdi.inf.br/site/artigos/Monografias\%20(Graduaca o)/Design $\% 20 \mathrm{de} \% 20$ Interacao $\% 20 \mathrm{e} \% 20$ Televisao $\% 20$ Digital $\%$ 20-\%20FREITAS.pdf $>$.Accessed on March 5, 2011.

[7] Gomes, Alex Sandro; Melo, Cássio; Arcoverde, Daniel; Monteiro, Bruno; Alves, Carina Frota. Design da Interação de Novos Produtos para TVD: Abordagens Qualitativas, in VIII Simpósio Brasileiro de Fatores Humanos em Sistemas 
Computacionais (IHC 2008), Full paper, Porto Alegre, Brasil, 2008.

[8] Gomes, Patrícia Cressoni. Simplicidade aplicada ao design interativo na TV digital: O desenvolvimento de aplicações com interfaces orientadas ao usuário e seu contexto de uso. Available at $<$ http://www.slideshare.net/paticress/simplicidadeaplicada-ao-design-interativo-na-tv-digital>. Acesso em: $02 \mathrm{de}$ jan de 2011.

[9] Junot, Regis Alvim. TV digital interativa: Uma nova mídia. Available

$<$ http://www.via.multimidia.nom.br/tvdi/tcc_regis_alvim_junot. pdf $>$. Accessed on January on January 2, 2011.

[10]Kotler, Philip. Administração de Marketing. $4^{a}$ edição. São Paulo: Editora Atlas, 1996.

[11]Lobach, Bernd; Van Camp, Freddy. Design industrial: bases para a configuração dos produtos industriais. São Paulo: Edgard Blücher, 2001

[12] Molich, Rolf; Nielsen, Jakob. Improving a human-computer dialogue, Communications of the ACM 33, 3 (March) 338-348, 1990.

[13] Norman, Donald A. O design do dia-a-dia. Rio de Janeiro: Rocco, 2006.

[14] Oliveira, Lílian Simão; Queiroz-Neto, José Pinheiro de; Maeta, Silvio M. A usabilidade em interfaces interativas no desenvolvimento de aplicativos para TV digital. II Congresso de Pesquisa e Inovação da Rede Norte Nordeste de Educação Tecnológica João Pessoa - PB - 2007. Available at http://www.redenet.edu.br/publicacoes/arquivos/20080110_150 450_INFO-002.pdf>. Accessed on January 2, 2011.

[15]Pereira, Alice Therezinha Cybis; Schmitt, Valdenise; Dias, Maria Regina Alvares C. Ambientes Virtuais de Aprendizagem. In: Ambientes Virtuais de Aprendizagem em Diferentes Contextos, Editora Ciência Moderna, Rio de Janeiro, 2007.

[16]Piccolo, Lara Schibelsky Godoy. Interação na TV digital: estudo e proposta de aplicação em governo eletrônico. Campinas, 2008. MSc thesis - Universidade Estadual de Campinas, Instituto de Computação.

[17]Preece, Jennifer; Rogers, Yvonne; Sharp, Helen. Design de interação: além da interação homem-computador. Porto Alegre: Bookman, 2005.

[18]Uzunboylu, Hüseyin, Bicen, Hüseyin e Cavus, Nadire. The Efficient Virtual Learning Environment: a case study of web 2.0 tools and Windows live spaces. Computers \& Education 56, 720-726, 2011

[19] Verplank, Bill. My PC, In: Designing Interactions, Moggridge, Bill, MIT Press, 2007. 